\title{
Structural Analysis and Topology Optimisation of an Aftercooler Cover for Weight Reduction in Off-Highway Engine Application
}

\author{
T. Murton ${ }^{1}$, R. Rahmani ${ }^{1 *}$, J. Crew ${ }^{2}$ \\ ${ }^{1}$ Wolfson School of Mechanical, Electrical and Manufacturing Engineering, Loughborough \\ University, Leicestershire, UK \\ ${ }^{2}$ Cummins Inc., Royal Oak Way South, Daventry, Northamptonshire, UK \\ *Corresponding author: R.Rahmani@lboro.ac.uk
}

\begin{abstract}
It is endeavoured to gain design direction by use of computational topology optimisation methods on off-highway engines to improve fuel economy and costs to the service provider via weight reductions. Most published studies are focused on key functional components of an on-highway vehicle that are required for the engine or vehicle to function. However, this study aims to use topology optimisation methods on the off-highway Cummins Inc. QSK78 aftercooler cover to achieve an improved design that at least maintains the current product performance, while the weight of the component is reduced. Such analysis has not hitherto reported in the context of offhighway vehicles. The method involves using topology optimisation techniques based on the given objectives relating to strain energy and natural frequencies. The topology optimisation results are used to provide an informed direction for the design of an optimised 3D CAD model. FEA is used to investigate the structural response of both the baseline and optimised covers. The final optimised design shows an improvement even at worst case of generated stress results while a weight reduction of $6.5 \%$ is achieved. It was concluded that further improvements could be made in the optimised design considering limitations due to customer constraints.
\end{abstract}

Keywords: Topology Optimisation; Aftercooler Cover; Structural Analysis; Engine Design

\section{Introduction}

In line with the stringent emission control requirements as well as the consumer demand on energy efficient products, the IC engine manufacturers are challenged with meeting those 
demands without substantial increase in cost of their products. Hence, one of the major focus areas is to reduce from the apparent inertia of the engine products while the functionality of the components and the system is uncompromised. Hence, reducing from the mass of the products can enhance the overall engine performance; helping to meet emissions regulations and tackle the fuel consumption.

Computational optimisation process is widely used for finding the optimum solution to such problems [1]. For a problem with a single objective function, it is normally expected that the optimisation process, with a set of identified input data, will provide a maximum (or minimum) value for the objective function. In real world engineering applications, it is often the case that a compromised solution should be sought when the main objective function is comprised of various functions with various designated weights. In such cases, a solution can be chosen from a Pareto frontier in which a desired trade-off is made amongst the influential parameters. In such a process, the optimum solution can be defined as the best solution for the objectives chosen whilst satisfying any imposing constraints. Computational optimisation utilises computational power to perform the optimisation and is currently used in many different fields, particularly within engineering [1]. Within the design industry, computational optimisation can be used to find the optimum design for the required function, size, weight or cost, to name a few objectives. The use of such optimisation methods can not only help to improve the overall design process, but also removes limitations that may be implicated on the problem by the designer making decisions based on previous experience.

The more popular types of optimisation used in design are shape, size, topometry, topography and more recently topology, first presented in 1988 by Bendsøe and Kikuchi [2]. Size optimisation is typically used to influence the materials cross-sectional area, thickness and material properties; often seen as a simplified version of topometry [3]. Shape optimisation is more focussed on changing the parameters such as chamfers, fillets, radii, etc. (i.e. the focus is more on changing the boundary surfaces of the structure). The algorithms used in this do not remove or add features but merely readjust those to achieve an optimum design [4].

Topography is considered as a more advanced or special form of shape optimisation. For instance, it is used to optimise sheet metal structures, where the objective could be to reduce 
displacement, maximise the natural frequency of the part, or increase the stiffness of shell structures [3].

Topometry optimisation is used when trying to identify design regions where material could be removed or where further material is required. It is a more advanced form of size optimisation that works on an element by element basis opposed to considering the part as a whole. The elements in topometry optimisation remain at the mid-plane i.e. do not offset like in topography. However, the element thickness does change, which therefore means it is not applicable to elements where thickness is not defined $([3,4])$

Topology optimisation also works on each element individually, which is explained in more detail later. One key advantage over other types of optimisation is the ability to remove material in 3D geometries. It is often considered important to realise where the need for material is and isn't within a structure. This leads to the idea of using topology optimisation to reduce the mass of structure by only having added material in key areas of the structure. This can prove useful in several applications where mass and structural robustness are key factors in the performance of the products. One example of mass having a large impact on product performance is the engine design industry. It has been found that reducing the mass of vehicles can reduce fuel consumption by 5-7\%; although this is not limited to changes of the engine only [5].

Therefore, the engine design industry is an excellent platform to implement topology optimisation to reduce the engine mass. It provides potential to improve the vehicle performance particularly in terms of fuel efficiency, whilst saving time and money in design, analysis, materials and manufacturing.

Optimisation is widely used in the automotive industry on many different components, mainly those under mechanical or structural loads. Some examples include brake pedals, engine mounts, MacPherson struts and connecting rods [6-9]. In most cases the optimisations performed are multi-objective, due to use of several objectives opposed to one. This can sometimes lead to an issue where no one solution is suitable, as the improvement or optimisation of one objective degrades another objective. This is otherwise known as a set of Pareto optimal, non-dominated, or non-inferior solutions, i.e. no one solution is outstanding. 
Cavazzuti and Splendi provide pictorial examples of how topology optimisation has been applied to different automotive components [10]. They considered application of topology optimisation to the Ferrari F458 front hood where a weight reduction of 12\% was achieved. The methodology used is an example of using topology optimisation to first realise key areas that material can be removed from, before improving the strength and reducing weight with topometry and/or size optimisation techniques.

In a separate study, Cavazzuti et al carried out the optimisation on an automotive chassis, based on performance and functional requirements by Ferrari standards [11]. One of the highlights in this report is regarding the design space. To provide the maximum amount of freedom for the optimisation process material was first added to the chassis; avoiding further restrictions on the optimisation.

As can be seen there is a wide use of topology optimisation on various key mechanically loaded or functional safety components. Further still, most the optimisations carried out are applied to the smaller on highway vehicles opposed to industrial off highway vehicles. There is limited application of topology optimisation to the technologies that are added to improve the overall efficiency of the engines, such as turbocharging and aftercooling systems. Hence, this investigation is intended to improve the benefits of such technologies by reducing the mass of the added components thus increasing fuel economy and lowering adverse emissions.

The current study focusses on applying topology optimisation to provide indications of the most suitable regions to reduce the mass of the Cummins QSK78 aftercooler cover as shown schematically in Figure 1, subject to constraints imposed by the customer including:

- Maintaining the internal geometry.

- Maintaining the bolted joints and connecting faces to avoid redesign of surrounding components.

The effect of these constraints will be realised after the topology optimisation has been carried out. It is important to note that the intention in the current study is not to optimise the current design but to provide a full design space for conducting topology optimisation with freedom to 
optimise the material layout within the design envelope. The result can then be further optimised using size optimisation techniques.

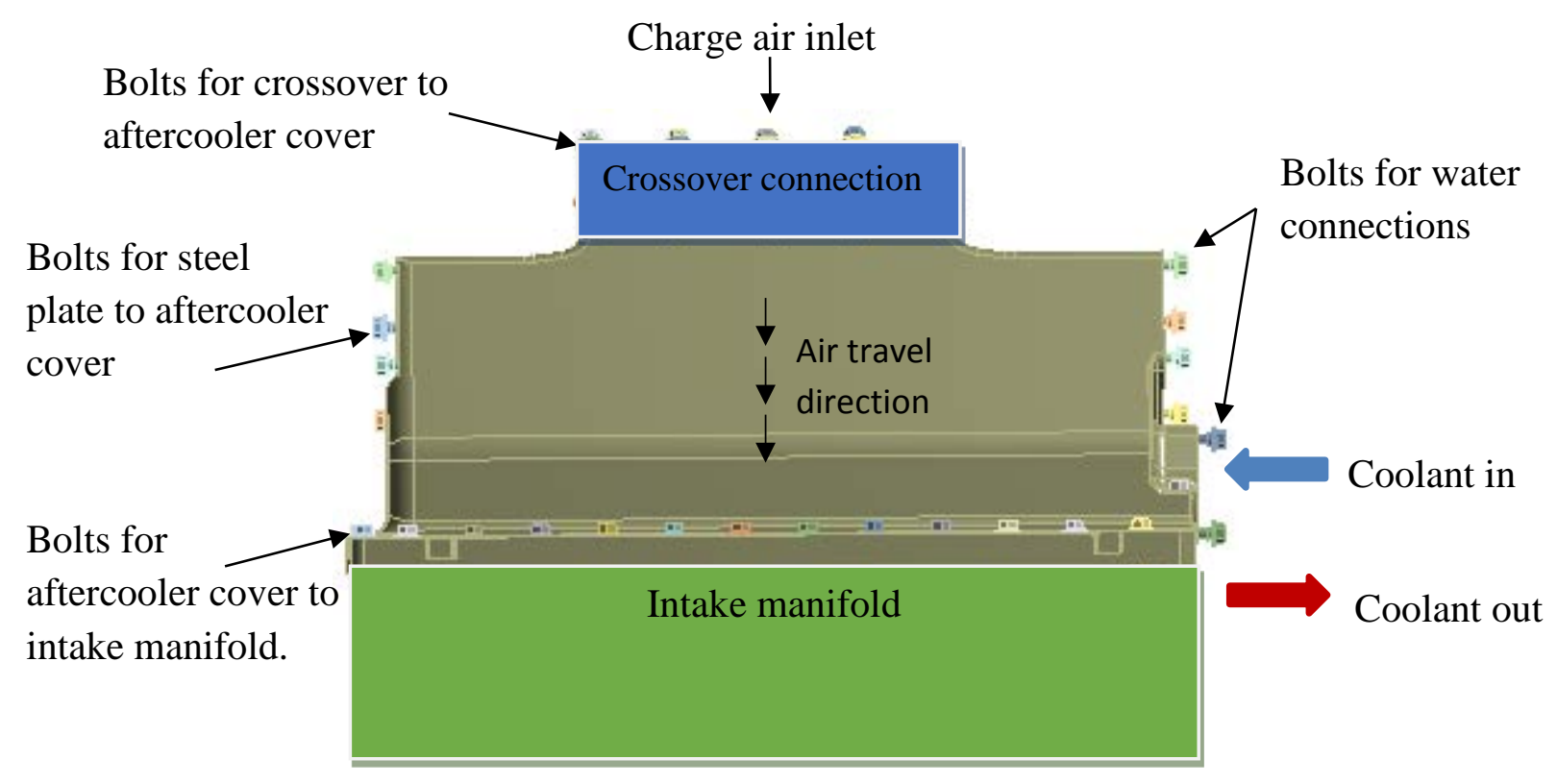

Cooler charge air exits to cylinder

Figure 1: Block layout of the aftercooler cover on a component level showing the direction of air and coolant, as well as the relevant components

\section{Theoretical Background}

The problem formulation in the current analysis follows that of BendsØe and Sigmund [12]. The problem formulation as described by BendsØe and Sigmund [12], for which the aim is to find the optimum stiffness tensor within a given design space, $\Omega$, in a discrete form, is as follows:

$\min _{u, \mathrm{E}_{\mathrm{e}}} \mathrm{F}^{T} u$

Subject to: $\quad \mathrm{K}\left(\mathrm{E}_{e}\right) u=\mathrm{F} \quad$ where, $E_{e} \in E_{a d} \quad$ and, $\mathrm{K}=\sum_{e=1}^{N} \mathrm{~K}_{e}\left(\mathrm{E}_{e}\right)$

where, $F$ is the load vector and $u$ is the displacement vector. $E_{e}$ represents the element stiffness, which is a member of the set of valid stiffness tensors, $E_{a d}$. K is the stiffness matrix composed of the elements stiffness matrix, $\mathrm{K}_{e}$, where $e=1, \ldots, N$. The objective stated is to minimise compliance, subject to the governing equation, $[\mathrm{K}]\{u\}=\{\mathrm{F}\}$, and the selection field, $E_{e}$. 
As described by BendsØe and Sigmund, topology is concerned with finding which points in the design space $(\Omega)$ should be material $\left(\Omega^{\text {mat }}\right)$ and which points shouldn't; all within the designable region (Figure 2). This is carried out by assigning points in space material properties that occupy that space, or zero properties where it does not.

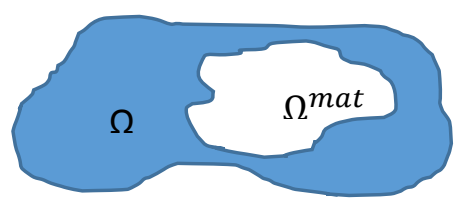

Figure 2: A schematic representation of the optimum material points within the designable region

More specifically, as stated by BendsØe and Sigmund [12], the admissible stiffness matrix consists of tensors for which:

$E_{i j k l}=1_{\Omega^{\text {mat }}} E_{i j k l}^{0}, \quad$ where, $1_{\Omega^{\text {mat }}}=\left\{\begin{array}{l}1 \text { if } x \in \Omega^{\text {mat }} \\ 0 \text { if } x \in \Omega \backslash \Omega^{\text {mat }}\end{array}\right.$

$\int_{\Omega} 1_{\Omega^{\text {mat }}} d \Omega=\operatorname{Vol}\left(\Omega^{\text {mat }}\right) \leq V$

As a result, $E_{a d}$ matrix will be formed by a combination of 0 's and 1's, providing a discrete value design problem. The stiffness tensor for the given material is represented by $E_{i j k l}^{0}$. This inequality introduces a material limit hence the potential for weight reduction.

There are a number of methods that have been developed over the years for solving the type of problems presented above. One such method is the more popular SIMP (Solid Isotropic Material with Penalisation) model $[12,13]$. The SIMP model is an interpolation method, where the density interpolates within the material properties, i.e. between 0 and $E_{i j k l}^{0}$ :

$E_{i j k l}(x)=\rho(x)^{p} E_{i j k l}^{0}, \quad$ where, $p>1$

$\int_{\Omega} \rho(x) d \Omega ; \quad 0 \leq \rho(x) \leq 1, \quad x \in \Omega$

Hence, the stiffness tensors would be assigned the following:

$E_{i j k l}(\rho=0)=0, \quad E_{i j k l}(\rho=1)=E_{i j k l}^{0}$ 
Therefore, to achieve a fully discrete value design, the density is required to be 0 or 1 at all points. As mentioned above (equation 5), $p$ (a penalty factor) should be greater than 1 , this is a way of penalising the intermediate densities which are not desired [2,12].

A second interpolation model is the RAMP (Rational Approximations of Material Properties) model. This model is better implemented when pressure loads are introduced. For concentrated loads, the SIMP model is the better interpolation scheme to use, as shown by Johnsen [3].

When it comes to more complex problems the implementation of a programming method is used to find the solution. Bendsøe and Sigmund [12] present the method of moving asymptotes (MMA) and CONLIN as two mathematical programming algorithms that are useful in topology optimisation. These algorithms are similar to some other algorithms such as Sequential Linear Programming (SLP) and Sequential Quadratic Programming (SQP) as they all begin by solving approximate sub problems. In MMA and CONLIN, the solution to the sub problem is used in the next design, which is solved again, and this is repeated until the optimum solution is found [12].

Sigmund [14] presents a similar topology problem to the one described above, using SIMP (power law). The article also describes some of the methods that can be used to solve the problem, but uses an Optimality Criteria (OC) method. The OC method is simpler, providing just one number that effectively defines how "good" the design/solution is. As it is a simpler method, it can be more easily implemented when writing a code.

\section{Methodology}

\subsection{Input data}

To carry out this study, the set of inputs given in Table 1 below were gathered. It is essential for these inputs to be correct in order to achieve a reliable solution for the defined problem.

Table 1: The important input requirements to carry out this optimisation problem

\begin{tabular}{|c|c|}
\hline QSK78 Aftercooler weight reduction inputs \\
\hline \multicolumn{2}{|c|}{ Geometry requirements } \\
\hline Item & Description \\
\hline
\end{tabular}

(c) 2016 Cummins Inc. All Rights Reserved. 
International Journal of Powertrains, 2017 (Accepted Version)

\begin{tabular}{|l|l|}
$\begin{array}{l}\text { Engine Assembly containing all 3D CAD } \\
\text { geometry }\end{array}$ & Used to model geometry \\
\hline \multicolumn{2}{|c|}{ Material Requirements } \\
\hline Aftercooler cover & Gray Cast Iron \\
\hline Intake Manifold & Gray Cast Iron \\
\hline Aftercooler Core & Measured mass data \\
\hline Air Crossover Connection & Aluminium \\
\hline Cylinder heads & Gray Cast Iron \\
\hline & Per ISO 898-1:2013 \\
\hline Bolt Preloads & Engine Test Data \\
\hline Internal Pressures & Engine Test Data \\
\hline Temperatures (Internal and External) & $\begin{array}{l}\text { Acquired from internal } \\
\text { database }\end{array}$ \\
\hline Thermal Coefficients (Internal and External) & Provided operational loads \\
\hline Static and shock loads &
\end{tabular}

In addition, the details of materials which were considered are listed in Table 2.

Table 2: Material data for the important common materials

\begin{tabular}{|l|c|c|c|c|c|}
\hline \multicolumn{6}{|c|}{ Material Information } \\
\hline Material & $\begin{array}{c}\text { Young's } \\
\text { modulus (GPa) }\end{array}$ & $\begin{array}{c}\text { Poisson's } \\
\text { ratio }\end{array}$ & $\begin{array}{c}\text { Density } \\
\left(\mathbf{k g} / \mathbf{m}^{3}\right)\end{array}$ & $\begin{array}{c}\text { Yield strength } \\
\text { (MPa) }\end{array}$ & $\begin{array}{c}\text { Ultimate tensile stress } \\
\text { (UTS) (MPa) }\end{array}$ \\
\hline Gray Iron & $80-150$ & $0.25-0.35$ & $6000-7500$ & $150-300$ & $300-400$ \\
\hline Aluminium & $60-100$ & $0.3-0.4$ & $2000-3500$ & $60-200$ & $100-250$ \\
\hline
\end{tabular}

\subsection{Topology optimisation process}

There were a few simplifications made in the finite element model to improve computational efficiency. The first assumption made was that the engine block had mass of an order high enough that any direct attachments could be considered fixed, hence, the block was removed. Secondly, all parts within a reasonable geometrical distance away could be removed, providing it would not affect the stiffness or mass on the system as both are key parameters in calculating natural frequencies. Finally, the crossover connected to the turbo through a hose. As the associated material properties and hence the stiffness for the hose were unknown, the decision was made to run the analysis as a worst-case problem. Essentially, this considers the hose to have negligible stiffness. Furthermore, the final assembly used throughout for the topology

(c) 2016 Cummins Inc. All Rights Reserved. 
optimisation purposes, neglected all bolts as the optimisation was not being carried out for bolt loads. This was also in line with the second customer requirements as mentioned earlier. The original (baseline) design used was that shown in Figure 3a and $\mathrm{b}$ below.

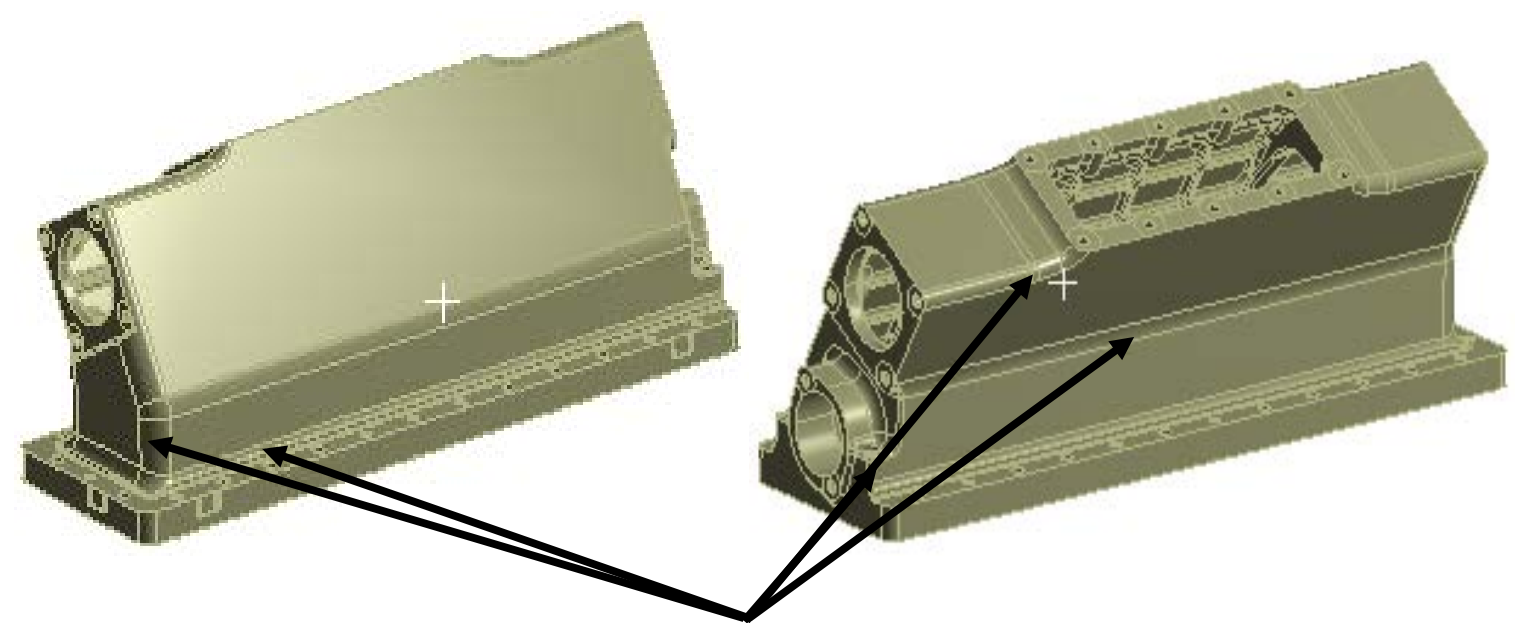

(a)

$$
\text { Removed features }
$$

(b)

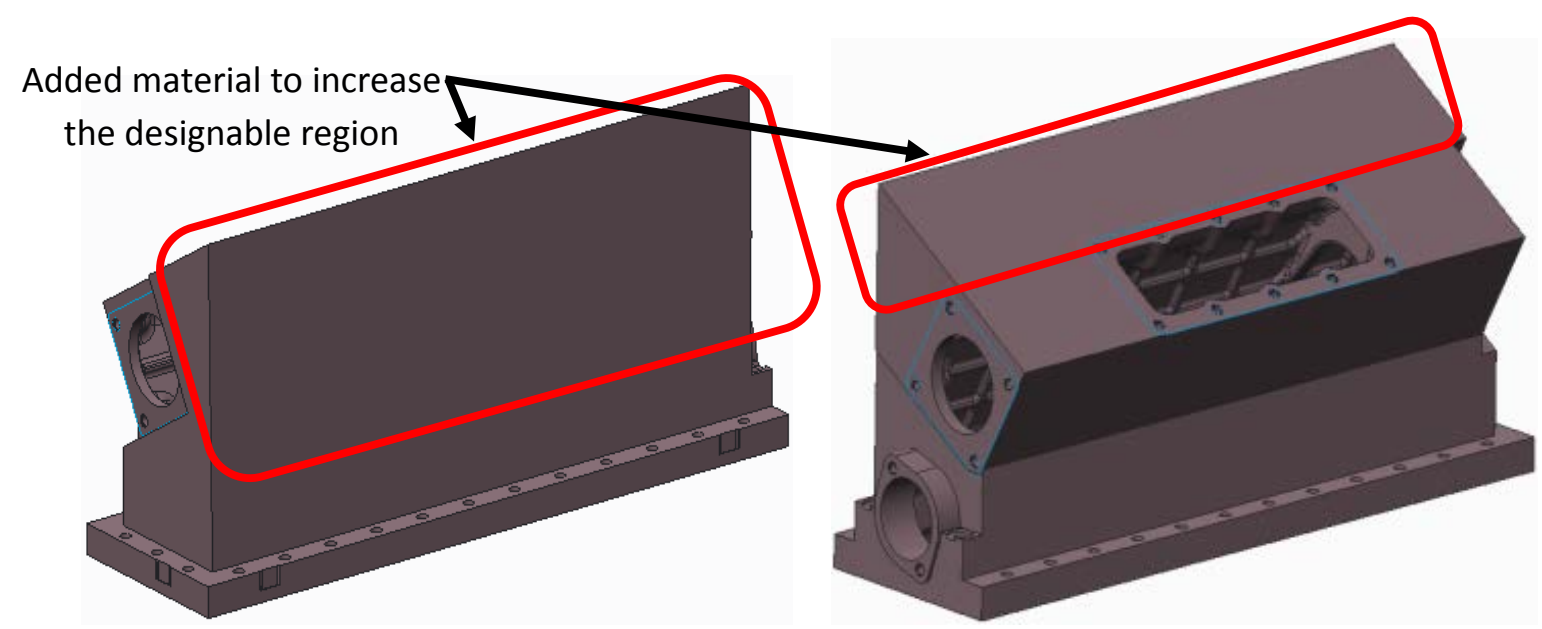

(c)

(d)

Figure 3: (a) Front and (b) back views of the initial baseline cover in which the fillets and chamfers were removed to reduce from meshing complexity; and (c) front and (d) back views of the cover with added material to increase designable (Note: internal surfaces are not part of design domain)

In processing the geometry, the aftercooler cover was modified to provide more design freedom during the topology optimisation. As stated in theory, the topology optimisation is carried out 
over the designable region, so to provide more freedom to the computation, material was added to the current cover increasing the designable region (See Figure 3c and d) to that of the available space envelope. The cover was also simplified by removing the fillets and chamfers on the cover.

With the geometry confirmed, the set-up within the analysis software could be carried out. As this analysis involves multiple objectives for each simulation, a weighting factor has been introduced, essentially prioritising the results of one function over the other. These are stated below. Two separate cases with different optimisation objectives were considered for the optimisation:

- Optimisation objectives 1: Increase natural frequency and reduce strain energy from operational loads with equal 50\% weightings.

- Optimisation objectives 2: Increase natural frequency and reduce strain energy from internal pressure with equal 50\% weightings.

It is expected that the topological alterations directly affect the strain energy through alterations in the stiffness tensor. In addition, the increment in the natural frequency should occur through either minimisation of the mass (inertia) or increasing the system stiffness. Since the type of material is not an optimisation parameter, this would be merely dependent on the topological alterations made throughout the optimisation process.

To optimise for the above objectives, it was necessary to carry out a modal and static stress analysis to provide the results for which the optimisation software tries to improve upon. The setup for both of these analyses involved a few common steps:

- Material assignment to each component.

- Connections: Contacts were created between all mating parts in the location of bolted joints.

- Computational mesh: All bodies except the aftercooler cover were applied a $15 \mathrm{~mm}$ size tetrahedral mesh elements. The aftercooler cover was meshed with a $5 \mathrm{~mm}$ element size with further refinement around the centre where more material was anticipated. This was to improve the final resolution in the optimised solution. 
With the geometry and mesh set-up complete, each individual analysis could be carried out considering the constraints and boundary conditions. The following describes the corresponding steps taken in the computational process:

- Modal analysis system: As the modal analysis does not require any force, only the constraints needed to be defined. As previously stated, the only constraint was to fix the cylinder heads around the bolts.

- Static structural analysis (used in the optimisation for service loads): fixed support was applied identical to that used in the modal analysis above. Further to this, accelerations were applied in 6 directions +/- X, Y and Z in 6 separate load steps.

- Static structural analysis (used in the optimisation for the internal pressure): The fixed supports were again set the same as that in the modal. A pressure was then applied normally to all internal faces of the intake manifold, aftercooler cover and crossover.

Finally, the optimisation could be set-up by defining the objectives as mentioned above, the designable region and the constraints related to the problem. In this case, the constraint was to use a fraction of the initial mass. This optimisation was carried out for three different mass fractions (MF) 0.1, 0.2 and 0.3, to provide a design direction. Although not implemented in this study, manufacturing considerations such as split lines or pull directions could be implemented; thereby tailoring the optimisation to the manufacturing; i.e. designing for manufacture.

\section{Results of Topology Optimisation}

Once the topology optimisation had been carried out with all three different mass fractions $(0.1$, $0.2,0.3$ ), there were six results of varying mass fractions that could be used to create a new design.

The results for Objective 1 at three described mass fractions are shown in Figures 4a, b and c. The colours within the figures provide clarity for where the existence of material is critical. The red colour shows the area where the material should not be removed, whilst the areas with cyan colour show where the material has already been removed. Other colours highlight areas for potential further material removal. It is shown in Figure 4a, optimisation with 0.3MF, that the front of the cover could have a uniform wall thickness whilst there are four distinguished ribs on the back of the cover. Figure $4 \mathrm{~b}$ shows for a $0.2 \mathrm{MF}$ a very similar result with a uniform wall (c) 2016 Cummins Inc. All Rights Reserved. 
International Journal of Powertrains, 2017 (Accepted Version)

thickness on the front of the cover and 4 ribs on the rear of the cover. The results for $0.1 \mathrm{MF}$ in Figure 4c show that effectively a uniform wall thickness would be the best solution for this amount of material as there are no ribs on the rear face of the cover. 


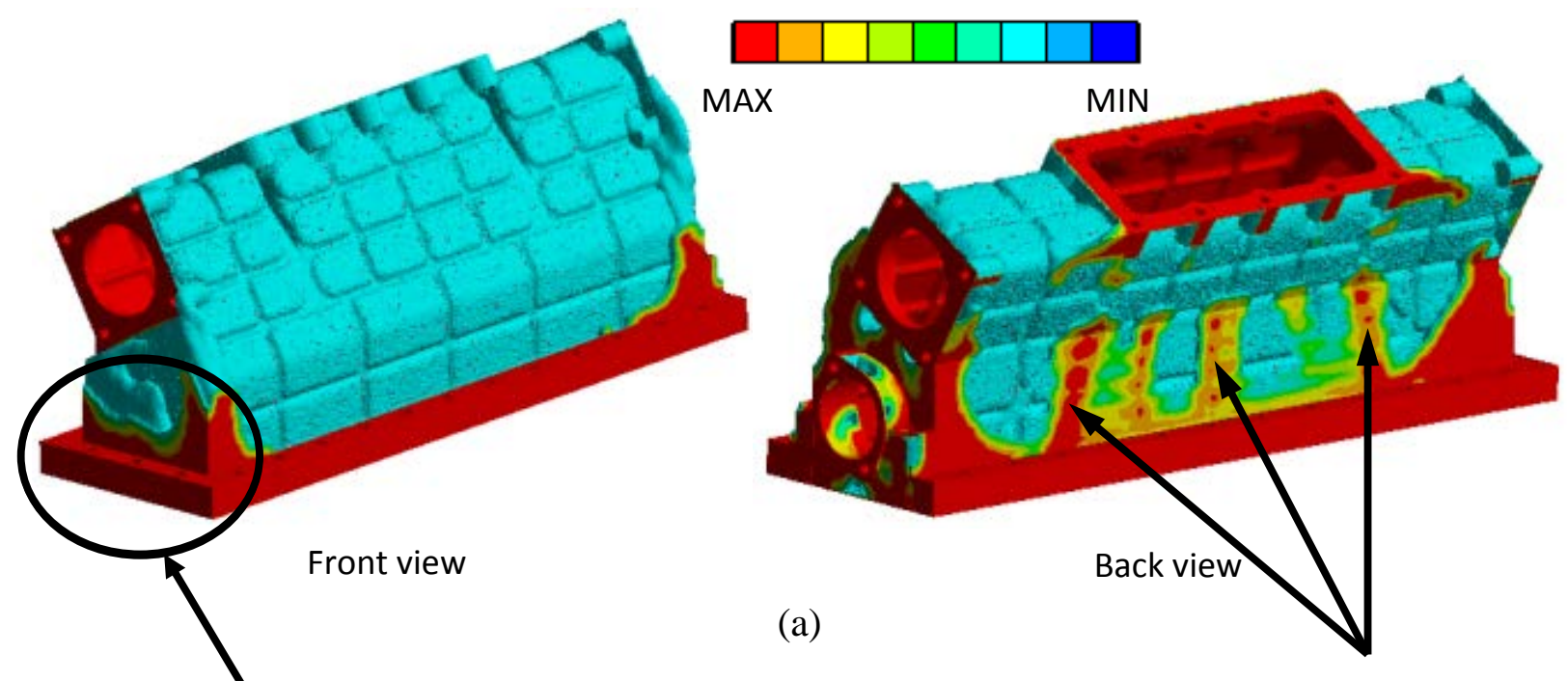

Area, where extra

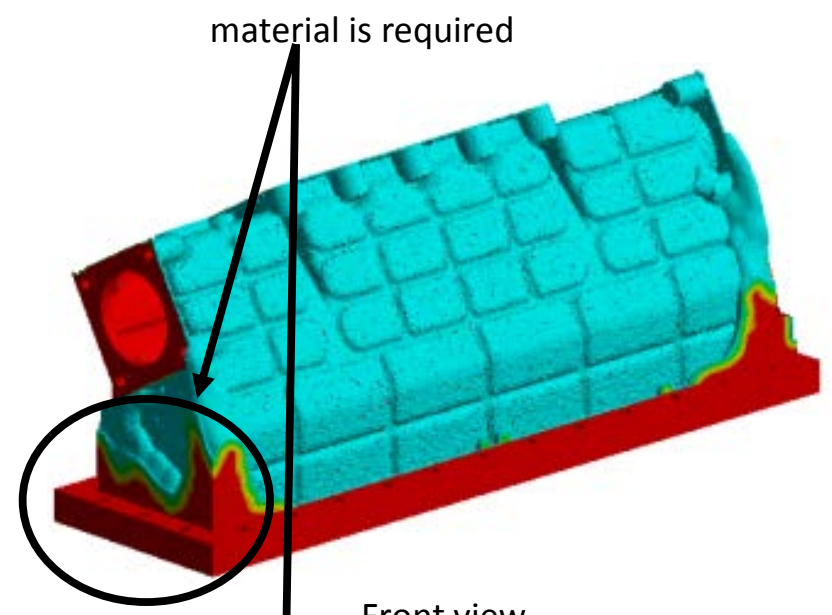

Front view

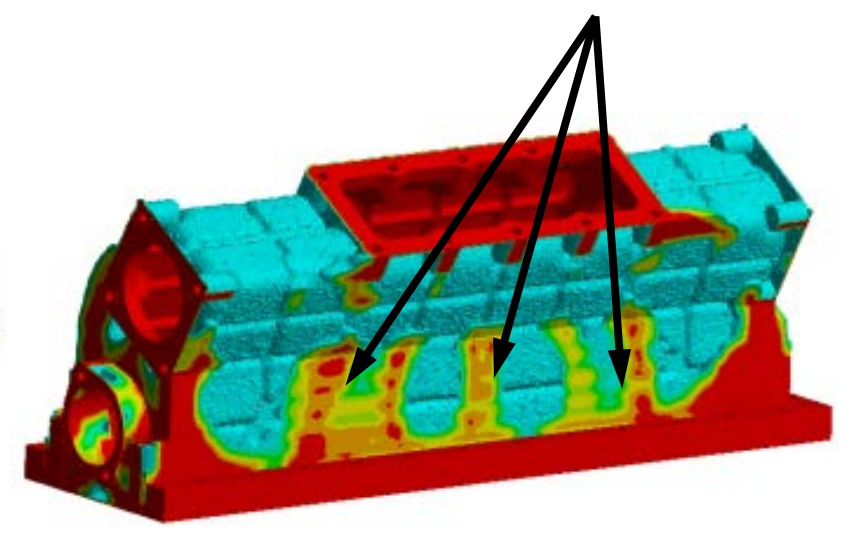

Back view

(b)

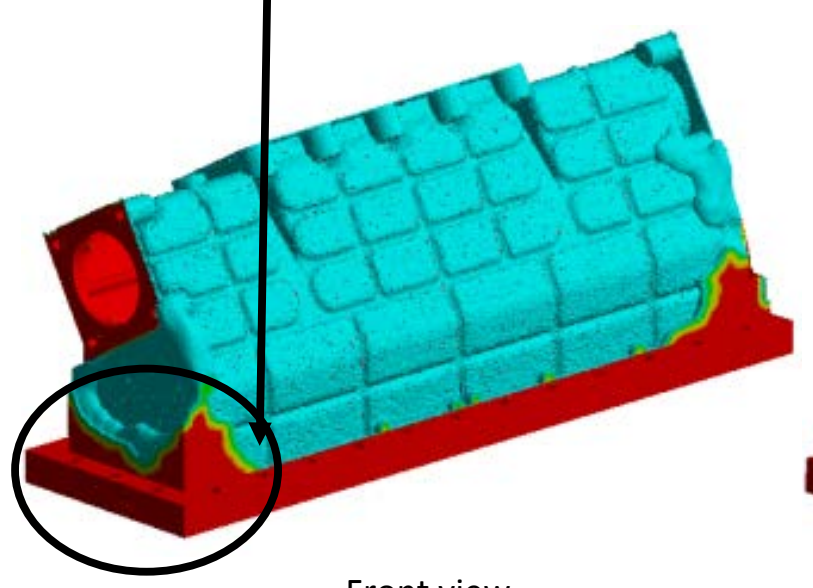

As the limit on allowable material is tightened a uniformly thick wall with no rib structure appeared

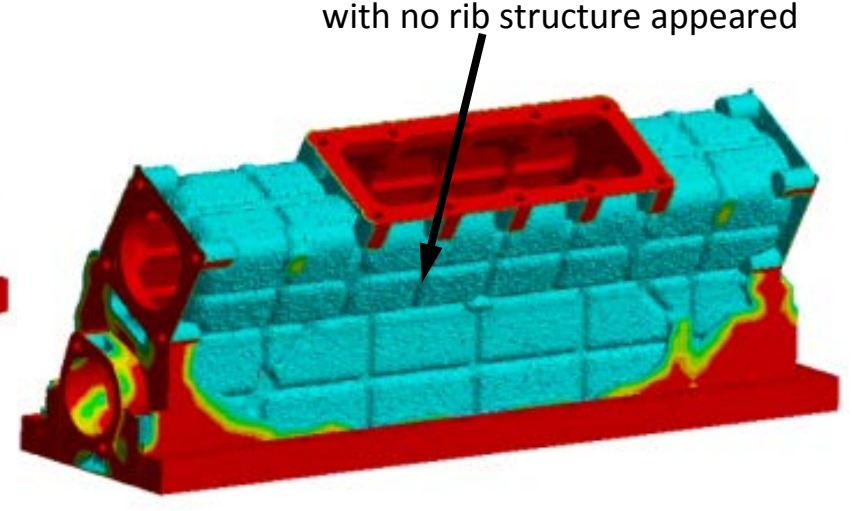

Back view

(c)

Figure 4: Optimisation for Objectives 1 with (a) $0.3 \mathrm{MF}$, (b) $0.2 \mathrm{MF}$ and (c) $0.1 \mathrm{MF}$ 
The results for Objective 2 at three described mass fractions are shown in Figures 5a, b and c. As it is shown in Figure 5a, optimisation with 0.3MF shows material arching across the front of the cover, whilst using the maximum possible material on the rear of the cover would be optimum. With a higher limit of allowable material, the rear face of the cover is thicker using all potential material. However, a substantial amount of material is removed from the front of cover. It should also be noted that the material along the front of the cover builds from the corners, further suggesting the previous idea that material on the corners help to improve the stiffness of the part. Figure $5 \mathrm{~b}$ for a $0.2 \mathrm{MF}$ shows material concentrated at the centre on the front of the cover, whilst some material on the rear can be removed in areas where its effect is not structurally significant. There is a significant amount of material on the front face of the cover around the top. As the allowable material limit is decreased, the material around the pointed area decreases and results in a more concentrated spot. On the rear side, as less material is allowed, the result show areas where material can be removed. In other words, the regions where material has been removed are regions which do not support much of the load (areas highlighted inside the boxed) thus not required.

The results for a $0.1 \mathrm{MF}$ in Figure 5c shows the requirement for a single rib down the centre on the front of the cover and necessary ribs on the back of the cover, if limited to this amount of material. In front view, the lowest limit of allowable material shows a small concentration of material in this centre location. This is to try and minimise the deformation and hence the stress as a result of the internal pressure, while in the rear view, the small regions with no material gradually increase as the material limit is tightened, resulting in a rib structure. This type of rib structure provides a good design direction for a designer to follow to give confidence on improving the stiffness of the structure. 
With a higher limit of allowable material, a thicker rear face whilst substantial amount of material is removed

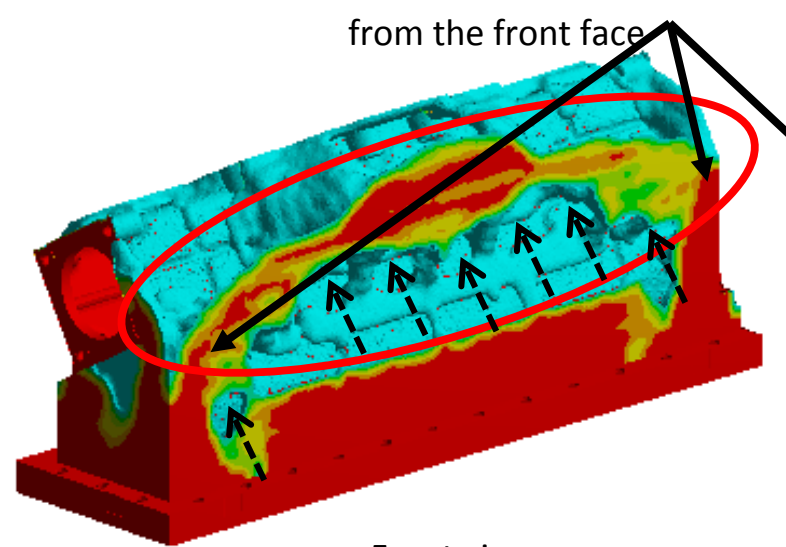

Front view

Extra material around the top (Reduction of material results in a more concentrated spot)

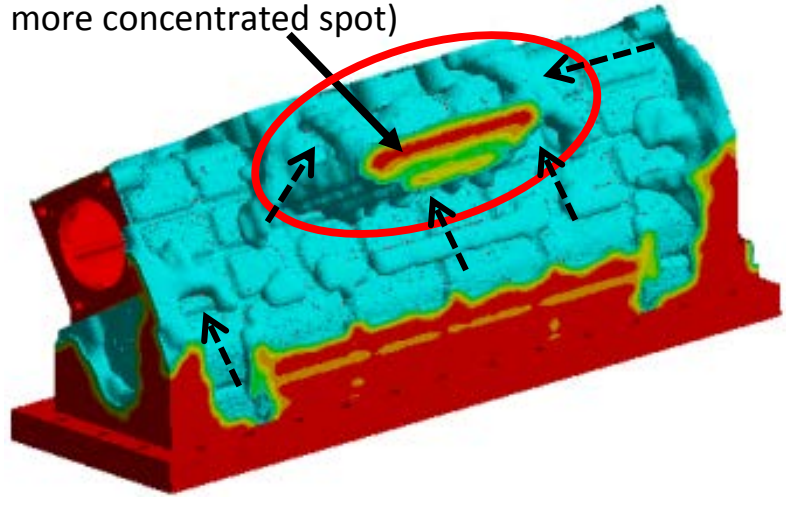

Front view

Small concentration of material in the centre location (this is to minimise the deformation and hence the stress as a result of the internal pressure) Front view
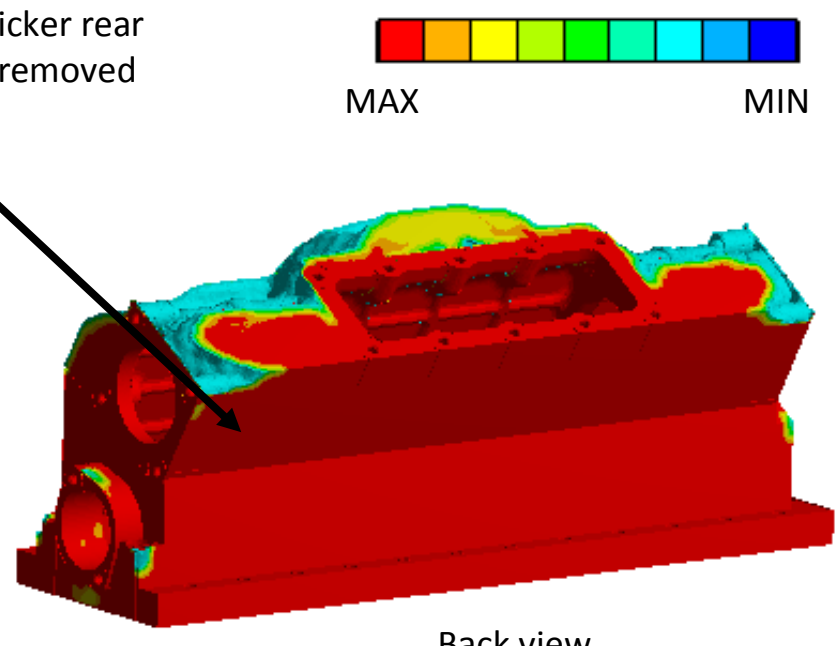

(a)

Material is removed from the regions that do not support the load

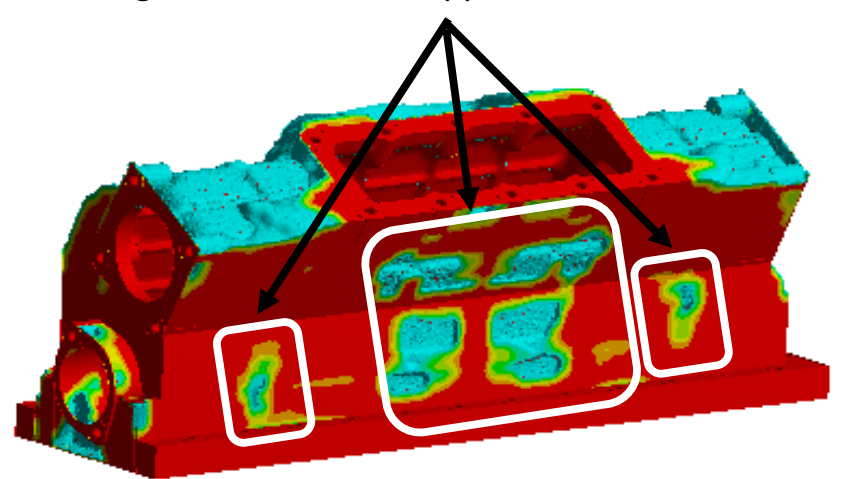

Back view

(b) Gradual rise in small regions of no material due to tightening of material limit, resulting in a rib structure

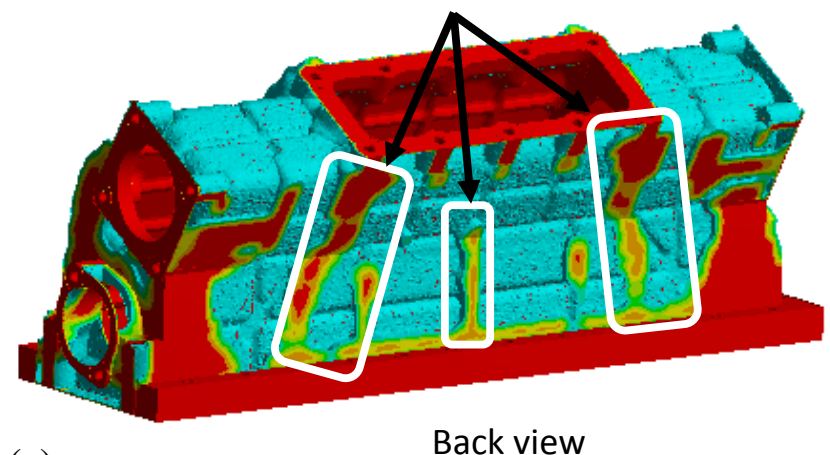

(c)
Back view

Figure 5: Optimisation results for Objective 2: (a) 0.3MF, (b) 0.2MF, (c) 0.1MF (Note: Dashed arrows point at the gaps (holes) in the optimised structure) 
As previously stated, the results obtained from the topology optimisation analysis in this section do not constitute a definitive design and are only intended to provide direction for the design changes that can reduce the overall mass of the component. It is important to realise that the method of manufacture may not allow for such complex geometry i.e. that shown in Figure 5c. Nevertheless, these can be used to provide "good" design direction and reasonable confidence that the final design would differ from the baseline design. It is clear to see from the results in Figure 5 that the pressure loads acting on the cover were dominant in terms of material requirements; hence it is reasonable to base the optimised design mainly off of the internal pressure optimisation results.

Figure 6 below shows the design idea generated based on the direction provided from the topology optimisation results. In Figure 6a it can be seen that the top oval section is mapped onto the cover (labelled 1 on the diagram) and bottom strip of material has been kept (labelled 2 on the diagram), as the results show in Figures $5 \mathrm{a}$ and $\mathrm{b}$. In addition, the centre rib is taken from the results shown in Figure 5c (labelled 3).

On the rear face of the cover, shown in Figure 6b, a general reduction in the thickness was achieved as well as the addition of ribs, taken from the results of MF0.1 show in Figure 5c (labelled 4). Further to the design changes made as a result of the topology, the fillet along the bolted joint flange was increased in radii to reduce the stress raiser (labelled 5). Although this design considers manufacturability in terms of aligning the design features with the pull direction of the moulds, in practice, a further verification step is required as to whether the topologically optimised design can be manufactured including accommodation of the angles.

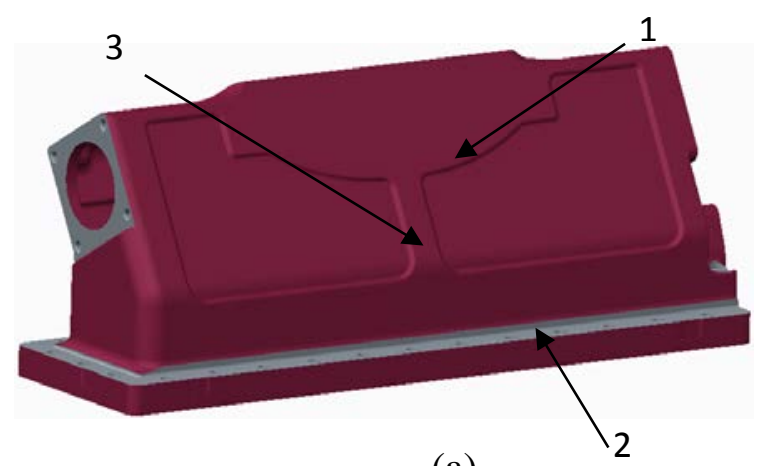

(a)

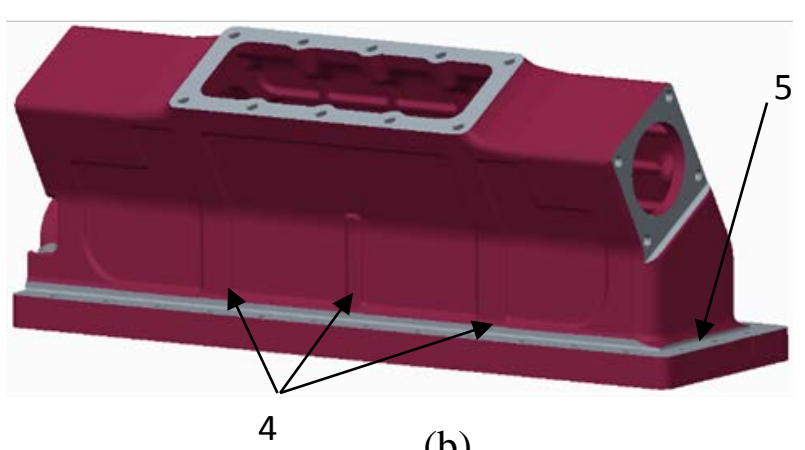

(b)

(c) 2016 Cummins Inc. All Rights Reserved. 
Figure 6: (a) front and (b) back views of the design chosen after topology optimisation process and also imposing the required constrains

The design shown in Figure 6 was then taken forward into the validation stage to realise if there has been any improvements. This optimised design has a weight reduction of $6 \%$ on the baseline cover.

\section{Validation Analysis}

The validation analysis was carried out on the original as well as the optimised cover as a means for direct comparison. The validation analysis utilised the original assembly as mentioned previously, but also included the bolts for the application of the bolt preloads. The analyses carried out were based on the performance requirements of the cover (see Table 3).

Table 3: The performance requirements to be investigated during validation analyses

\begin{tabular}{|c|c|c|}
\hline Analysis & Requirement 1 & Requirement 2 \\
\hline Modal & $\begin{array}{l}\text { Natural frequency to be outside of excitation } \\
\text { frequency }\end{array}$ & Check the vibrational fatigue of the cover \\
\hline $\begin{array}{l}\text { Structural } \\
\text { analysis }\end{array}$ & $\begin{array}{l}\text { Cover should not exceed material yield limit } \\
\text { under pressure or operational loads }\end{array}$ & $\begin{array}{c}\text { Factor of strength (FOS) should be } \\
\text { calculated for the cycle of assembly to each } \\
\text { operational load, i.e. A-OL1 }\end{array}$ \\
\hline Thermal & $\begin{array}{l}\text { Investigate the temperature gradient to } \\
\text { ensure it is realistic }\end{array}$ & \\
\hline $\begin{array}{l}\text { Bolted } \\
\text { joints }\end{array}$ & $\begin{array}{l}\text { Calculate the clamp load margin for internal } \\
\text { pressure. } \\
\text { Calculate bolt shear margins for operational } \\
\text { loads }\end{array}$ & $\begin{array}{l}\text { Calculate clamp load margin for modal } \\
\text { analysis }\end{array}$ \\
\hline \multicolumn{3}{|c|}{$\begin{array}{l}\text { The general set-up of the analysis was the same as that for the static-structural and modal } \\
\text { analyses as described above for the topology optimisation. The only difference was how the } \\
\text { boundary conditions in the structural and thermal analyses were set. The structural analysis } \\
\text { required acceleration loads, whereas the thermal analysis requires thermal loads and heat } \\
\text { coefficients. }\end{array}$} \\
\hline
\end{tabular}

In the static stress analysis a combination of load cases were used. These included:

-Load case 1: An assembly load case simulating the torque application to bolted joints (A) 
-Load case 2: Assembly and pressure load case consisting of the torque application and internal pressure simulating the pressure as a result of charge air (AP)

-Load cases 3-8: Combinations of inertial accelerations as measured on engine (Table 4)

Table 4: The operational loads (OL) are described in terms of recorded accelerations as measured on engine during operation (X: with acceleration and 0: no acceleration)

\begin{tabular}{lccc}
\hline Load Case & X-Lateral $\left(\frac{m}{s^{2}}\right)$ & y-Vertical $\left(\frac{m}{s^{2}}\right)$ & z-Axial $\left(\frac{m}{s^{2}}\right)$ \\
\hline Operational Load 1 (OL1) & 0 & $\mathrm{X}$ & $\mathrm{X}$ \\
\hline Operational Load 2 (OL2) & 0 & $\mathrm{X}$ & $\mathrm{X}$ \\
\hline Operational Load 3 (OL3) & $\mathrm{X}$ & $\mathrm{X}$ & 0 \\
\hline Operational Load 4 (OL4) & $\mathrm{X}$ & $\mathrm{X}$ & 0 \\
\hline Operational Load 5 (OL5) & 0 & $\mathrm{X}$ & 0 \\
\hline Operational Load 6 (OL6) & 0 & $\mathrm{X}$ & 0 \\
\hline
\end{tabular}

The thermal analysis required application of heat transfer coefficient's to all surfaces in the assembly and thermal loads were added to the internal surfaces in the form of convection from the passing hot charge air entering the aftercooler. The thermal loads used were representative temperatures, measured during engine testing. The thermal heat coefficients for each surface was also supplied and applied to the surfaces accordingly.

For the bolted joint analysis, the bolts and preloads were removed and mating surfaces were connected through contacts. The same loading and constraints as used in the validation analysis (except the bolt preloads, load case 1) were applied so the required force at each surface could be calculated under the different loading conditions.

After completion of the analysis, the results from the baseline and optimised covers were compared in order to realise the improvements and drawbacks of the new design.

\section{Analysis Results}

\subsection{Modal analysis}

The first and only natural frequency within the engine operating range and subsequent mode shape can be seen in Figures $7 \mathrm{a}$ and $\mathrm{b}$ for the baseline and optimised covers before and after thermal loading. 


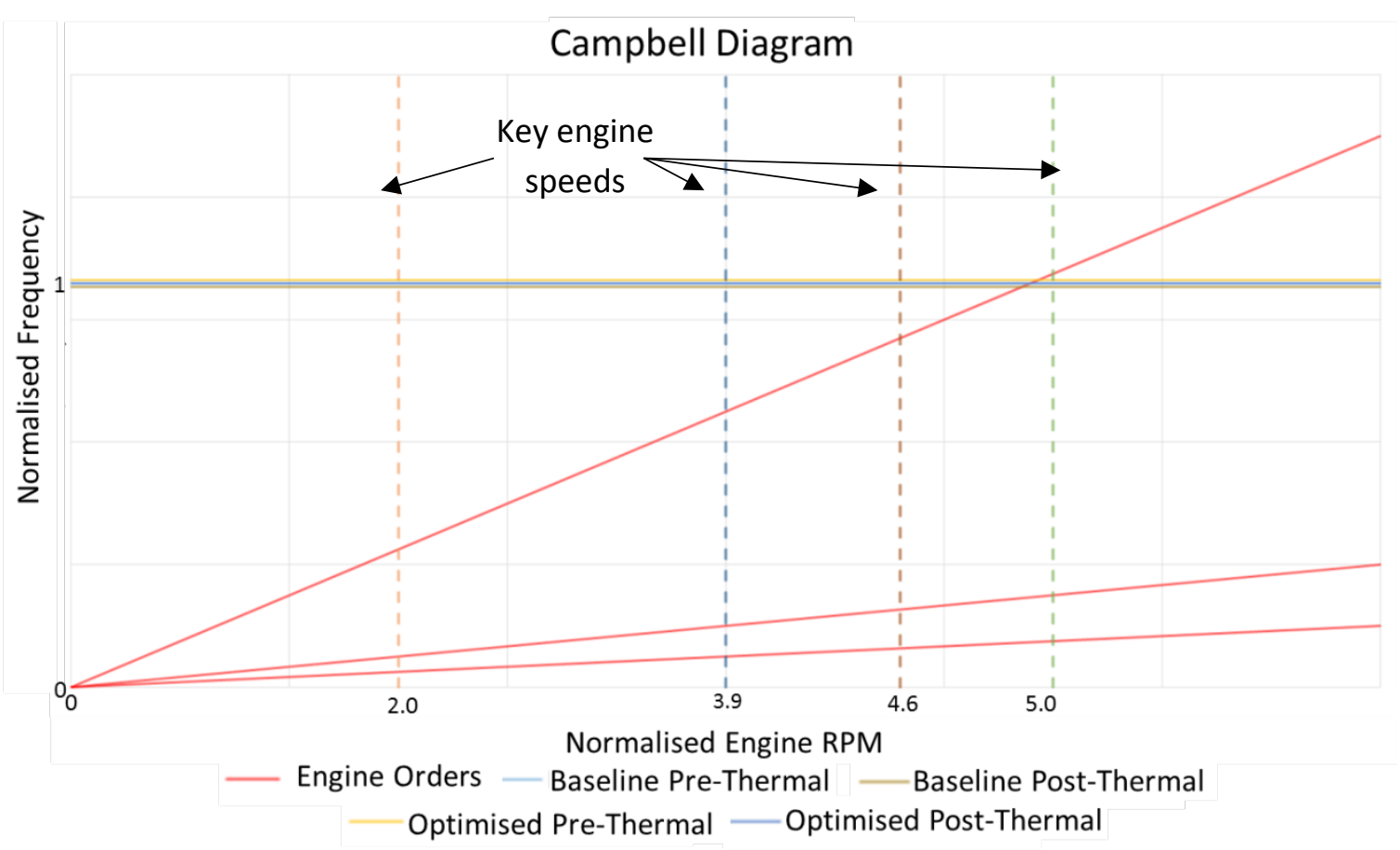

(a)

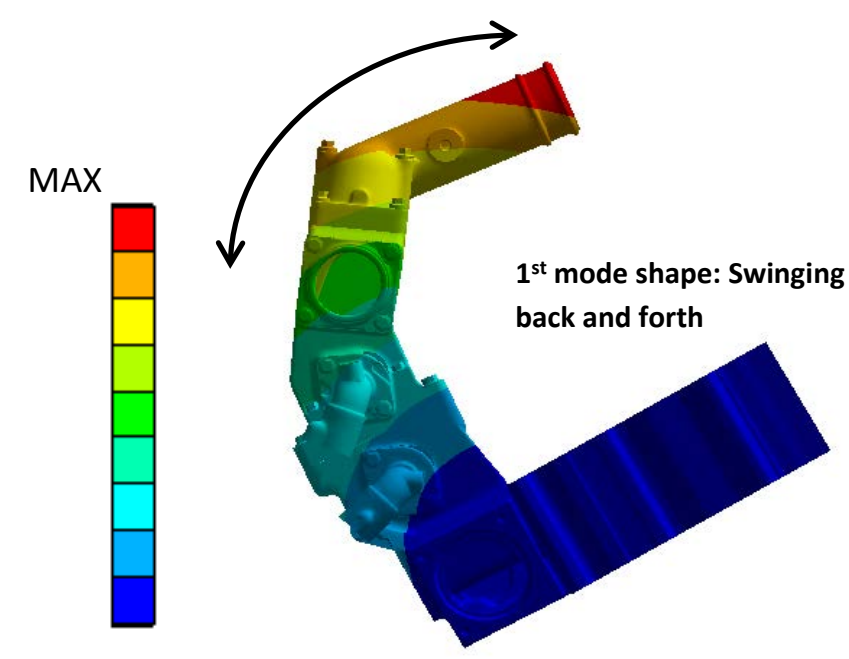

MIN

(b)

Figure 7: (a) Campbell diagram showing the natural frequencies in comparison to excitations frequencies and (b) visualisation of the corresponding mode shape

The mode shape for this natural frequency was the same for both covers with and without thermal loading. The main information to take from the modal analysis is the natural frequency and the mode shape. Figure $7 \mathrm{~b}$ shows the region of maximum deformation however the magnitude is 
arbitrary within the analysis and therefore not relevant. There was next to no difference in the modal results between the two covers.

As this mode was close to the excitation frequency of a dominant engine order, the component was revaluated to find the maximum amount of inertial load it could withstand without fatiguing. Table 5 presents the worst case values, which are in same location as that shown in Figure 14.

Table 5: The minimum acceleration threshold for the optimised design and baseline cover pre and post thermal loads

\begin{tabular}{llcc}
\hline & & $\begin{array}{c}\text { Minimum acceleration } \\
\text { threshold }\end{array}$ & $\begin{array}{c}\text { Does it meet minimum } \\
\text { requirements? }\end{array}$ \\
\hline \multirow{2}{*}{ Baseline cover } & Pre-thermal & 1.00 & Yes \\
\cline { 2 - 4 } & Post-thermal & 1.00 & Yes \\
\hline \multirow{2}{*}{ Optimised cover } & Pre-thermal & $-12.36 \%$ & Yes \\
\cline { 2 - 4 } & Post-thermal & $24.00 \%$ & Yes \\
\hline
\end{tabular}

\subsection{Structural analysis}

The response of the baseline and optimised covers to the internal pressure loading and additional operational loads can be seen in Table 6 for pre-thermal and Table 7 for post-thermal analysis. These tables present the highest (worst) stress values located on the covers compared with the material stress limits. The optimised cover margins are relative to the baseline margins and the locations listed in the tables can be seen in Figures 12 and 13 respectively.

Table 6: Pre-thermal static stress analysis results used to observe the effects on stresses because of the design change

\begin{tabular}{|c|c|c|c|c|c|c|c|}
\hline \multirow[b]{2}{*}{$\begin{array}{l}\text { Pre- } \\
\text { thermal }\end{array}$} & \multicolumn{2}{|c|}{$\begin{array}{l}\text { Baseline Cover } \\
\text { Results }\end{array}$} & \multicolumn{2}{|c|}{ Optimised cover Results } & \multirow[b]{2}{*}{$\begin{array}{l}\text { Does it meet } \\
\text { requirements? }\end{array}$} & \multicolumn{2}{|c|}{$\begin{array}{c}\text { Location of worst case } \\
\text { stress }\end{array}$} \\
\hline & $\begin{array}{l}\text { Yield } \\
\text { Margin }\end{array}$ & $\begin{array}{l}\text { UTS } \\
\text { Margin }\end{array}$ & $\begin{array}{l}\% \text { Diff } \\
\text { Yield } \\
\text { Margin }\end{array}$ & $\begin{array}{l}\text { \% Diff } \\
\text { UTS } \\
\text { Margin }\end{array}$ & & Baseline & Optimised \\
\hline Preload & 1.69 & 2.60 & -1.54 & -1.54 & Yes & 2 & 4 \\
\hline Pressure & 1.02 & 1.57 & 11.18 & 11.18 & Yes & 1 & 1 \\
\hline OL 1 & 1.03 & 1.59 & 11.31 & 11.31 & Yes & 1 & 1 \\
\hline OL 2 & 1.01 & 1.55 & 11.09 & 11.09 & Yes & 1 & 1 \\
\hline OL 3 & 1.00 & 1.54 & 10.83 & 10.83 & Yes & 1 & 1 \\
\hline OL 4 & 1.05 & 1.61 & 11.59 & 11.59 & Yes & 1 & 1 \\
\hline OL 5 & 1.02 & 1.57 & 11.34 & 11.34 & Yes & 1 & 1 \\
\hline OL 6 & 1.02 & 1.57 & 11.05 & 11.05 & Yes & 1 & 1 \\
\hline
\end{tabular}

(c) 2016 Cummins Inc. All Rights Reserved. 
Table 7: Post-thermal static stress analysis results under the same loading, used to observe the effects on the stresses as a result of the design change

\begin{tabular}{llllllll}
\hline & \multicolumn{2}{l}{$\begin{array}{l}\text { Baseline Cover } \\
\text { Results }\end{array}$} & & \multicolumn{2}{l}{ Optimised cover Results } & & \multicolumn{2}{c}{$\begin{array}{l}\text { Location of worst case } \\
\text { stress }\end{array}$} \\
\cline { 2 - 6 } thermal & $\begin{array}{l}\text { Yield } \\
\text { Margin }\end{array}$ & $\begin{array}{l}\text { UTS } \\
\text { Margin }\end{array}$ & $\begin{array}{l}\text { \% Diff } \\
\text { Yield } \\
\text { Margin }\end{array}$ & $\begin{array}{l}\text { \% Diff } \\
\text { UTS } \\
\text { Margin }\end{array}$ & $\begin{array}{l}\text { Does it meet } \\
\text { requirements? }\end{array}$ & Baseline & Optimised \\
\hline Preload & 1.76 & 2.71 & 3.81 & 3.81 & Yes & 5 & 4 \\
\hline Pressure & 1.20 & 1.85 & 9.96 & 9.96 & Yes & 1 & 3 \\
\hline OL $\mathbf{1}$ & 1.22 & 1.88 & 8.88 & 8.88 & Yes & 1 & 3 \\
\hline OL $\mathbf{2}$ & 1.19 & 1.83 & 10.67 & 10.67 & Yes & 1 & 3 \\
\hline OL $\mathbf{3}$ & 1.17 & 1.80 & 13.24 & 13.24 & Yes & 1 & 1 \\
\hline OL $\mathbf{4}$ & 1.24 & 1.90 & 6.34 & 6.34 & Yes & 1 & 3 \\
\hline OL $\mathbf{5}$ & 1.20 & 1.85 & 7.69 & 7.69 & Yes & 1 & 3 \\
\hline OL $\mathbf{6}$ & 1.20 & 1.85 & 11.31 & 11.31 & Yes & 1 & 1 \\
\hline
\end{tabular}

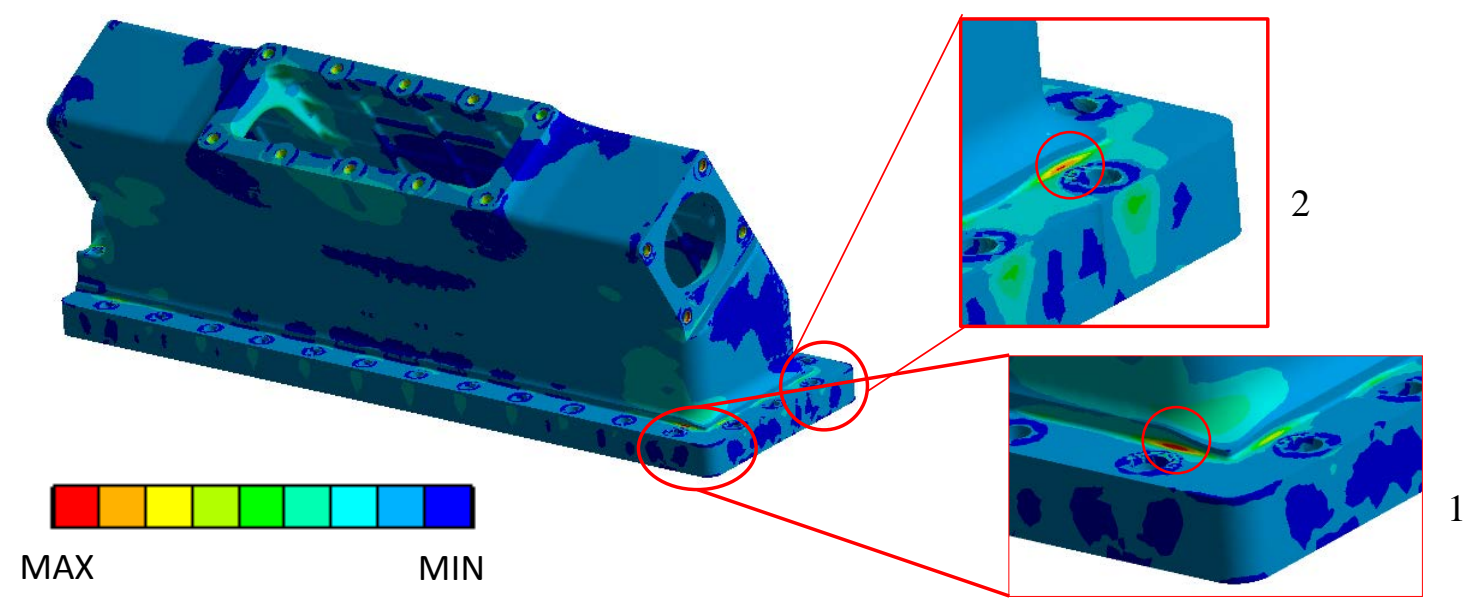

Figure 12: Locations 1 and 2 of the two high stress regions are both located in the small fillet behind the bolts. Such small radii are expected to act as a stress raisers 


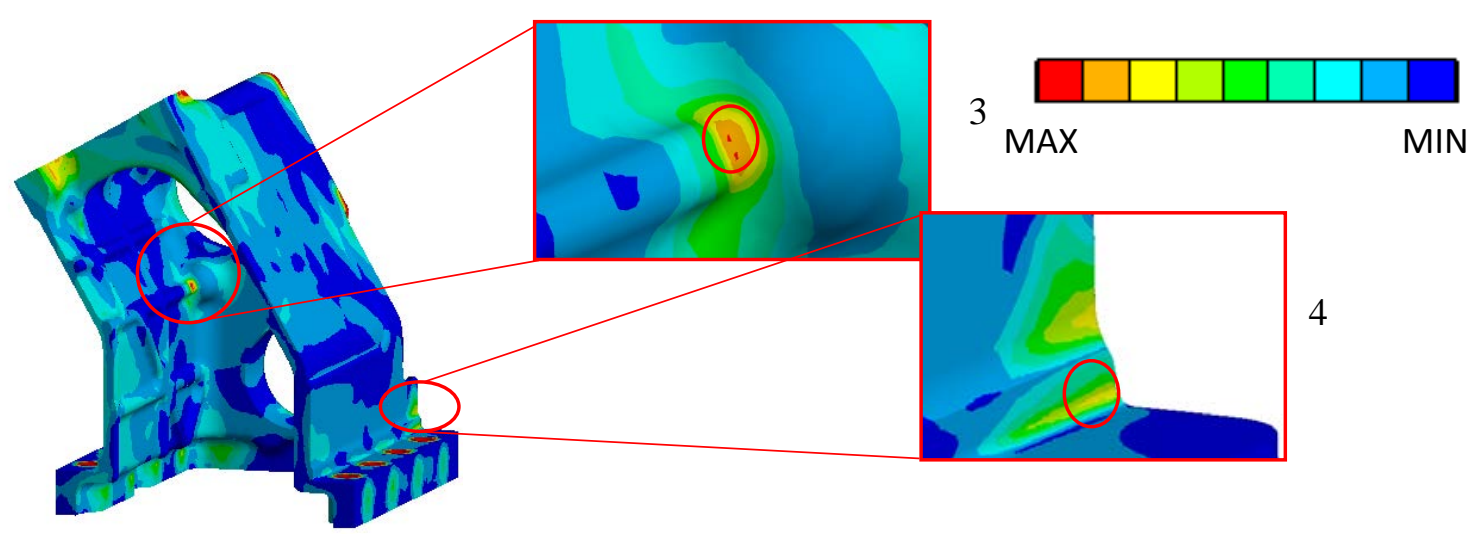

Figure 13: Locations 3 and 4 of the high stress areas. Location 3 is internal to the cover unlike the other high stress locations

\subsection{Fatigue calculations}

The fatigue life can be evaluated effectively by using a parameter named factor of strength. This provides a margin of the expected life to design life. Therefore, the factor of strength (FOS) was evaluated for the part using the stress values obtained in the static stress analysis. There were a number of cycles for which fatigue was calculated. The results for the different stress states can be seen in Table 8.

Table 8: The FOS value comparing the baseline cover and the optimised cover for both pre and post thermal analysis under operational loading

\begin{tabular}{|c|c|c|c|c|}
\hline \multirow{2}{*}{$\begin{array}{l}\text { FOS for } x \text { number of Cycles } \\
\text { under the cycles below }\end{array}$} & \multicolumn{2}{|c|}{ Baseline Cover Results } & \multicolumn{2}{|c|}{ Optimised Cover Results } \\
\hline & FOS Pre-thermal & FOS Post-thermal & \% Difference & \% Difference \\
\hline A-AP & 1.00 & 1.07 & 15.52 & 8.08 \\
\hline AP-OL1 & 4.00 & 4.00 & - & - \\
\hline AP-OL2 & 4.00 & 4.00 & - & - \\
\hline AP-OL3 & 4.00 & 4.00 & - & - \\
\hline AP-OL4 & 4.00 & 4.00 & - & - \\
\hline AP-OL5 & 4.00 & 4.00 & - & - \\
\hline AP-OL6 & 4.00 & 4.00 & - & - \\
\hline
\end{tabular}

It should be noted that the value of 4 means the FOS is beyond the limit calculated; i.e. the actual FOS exceeds the limits substantially so is not considered, hence no definitive percentage difference can be defined. The worst case FOS was in the same location for both covers as shown in Figure 14 below.

(C) 2016 Cummins Inc. All Rights Reserved. 


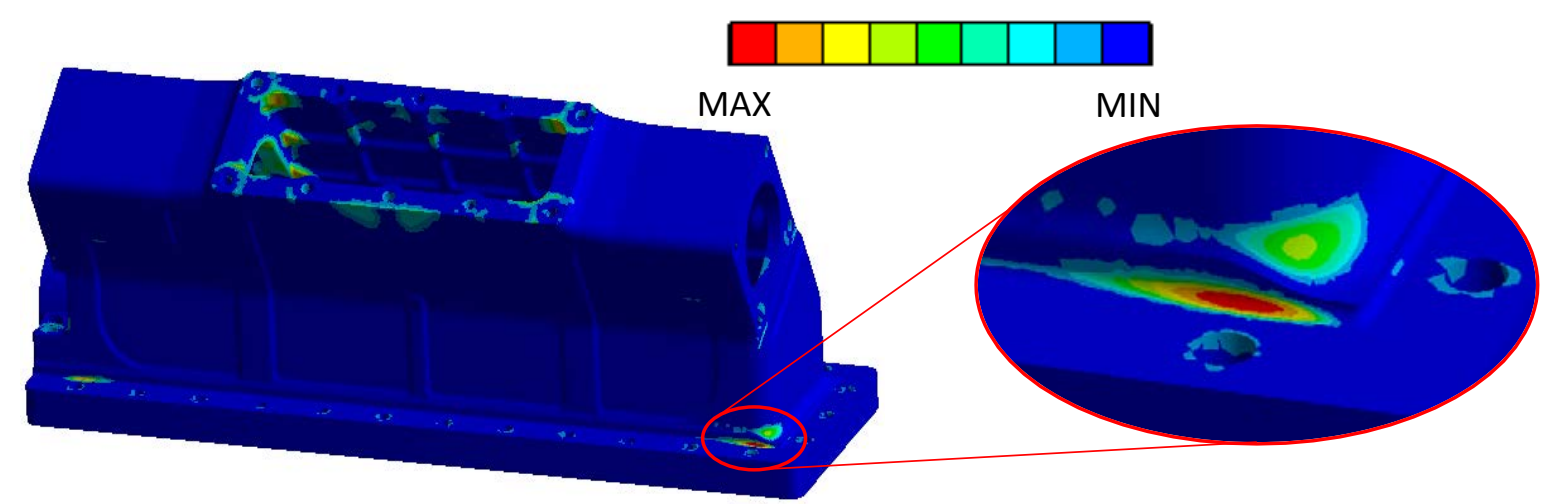

Figure 14: Location of the lowest life, as expected, due to being one of the highest stressed locations with lowest acceleration threshold

\subsection{Bolted joints}

The bolted joints were evaluated for non-thermal conditions only. The clamp load margin is calculated by comparing the required force of the bolt (extracted from the reaction forces in the analysis) and compared to the available force of the bolt i.e. bolt pre-load. The clamp load margins for both baseline and optimised covers under internal pressure can be seen in Figures 15 and 16, where bolts 101-129 are bolts on the bottom flange of the cover and bolts 201-210 are the bolts on the top of the cover. The key thing to note in this comparative study of the bolts is the difference between the two. These results indicate that the forces required by the bolts do not change greatly.

Clampload Margins for the load case 2 (Assembly + Pressure) for bolts 101-129

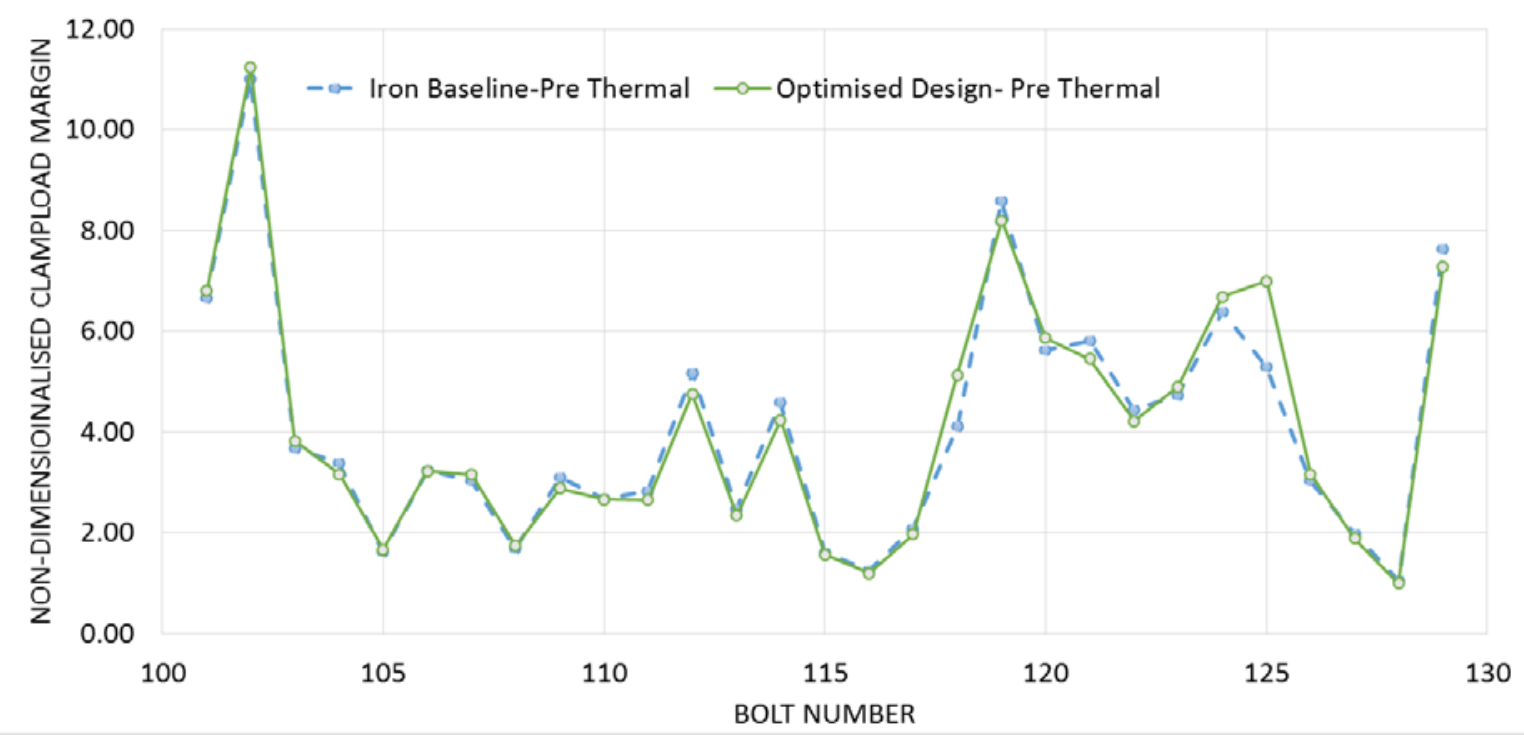

(c) 2016 Cummins Inc. All Rights Reserved. 
Figure 15: Comparison of baseline and optimised covers for the bolted joints between the aftercooler cover and intake manifold

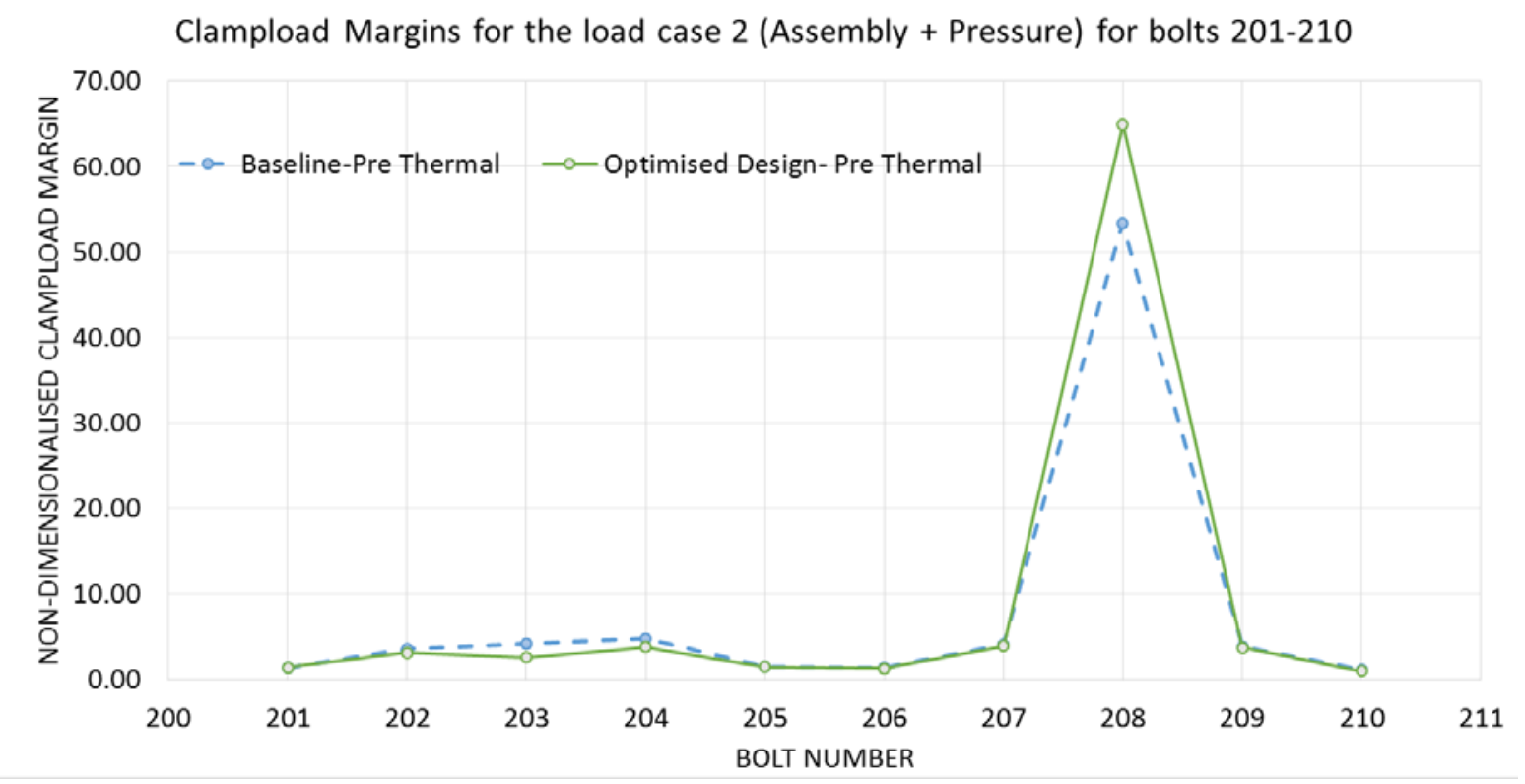

Figure 16: Comparison of baseline and optimised covers for the bolted joints between the aftercooler cover and crossover

As per the requirements, the shear margin was calculated for all bolts subject to the operational loads (OL 1 to 6). The shear margin is a comparison between the shear strength of the bolt to the shear forces acting on it. The worst case shear margin and the bolt number for both the optimised and baseline cover can be seen in Table 9 for bolts 101-129 and Table 10 for bolts 201-210. The results generally show that there is a small change in the shear forces acting on the bolt under loading conditions as a result of this design change.

Table 9: The worst case shear margins for the bolts 101-129 with both covers. The results are for pre- and post-thermal analyses

\begin{tabular}{llllllll}
\hline \multirow{2}{*}{$\begin{array}{l}\text { Bolts 101-129 } \\
\text { Shear Margin }\end{array}$} & & \multicolumn{6}{c}{ Operational Load (OL) Case } \\
\cline { 2 - 8 } Baseline Cover & Worst case Shear Margin & $\mathbf{3}$ & $\mathbf{4}$ & $\mathbf{5}$ & $\mathbf{6}$ & $\mathbf{7}$ & $\mathbf{8}$ \\
\cline { 2 - 8 } & Bolt Number & 113 & 113 & 128 & 113 & 113 & 128 \\
\hline \multirow{2}{*}{ Optimised Cover } & Worst case Shear Margin & 2.10 & 2.06 & 1.96 & 2.10 & 2.14 & 1.95 \\
\cline { 2 - 7 } & Bolt Number & 113 & 113 & 128 & 113 & 113 & 128 \\
\hline
\end{tabular}

(c) 2016 Cummins Inc. All Rights Reserved. 
Table 10: The worst case shear margins for the bolts 201-210 with both covers. The results are for pre- and post-thermal analyses

\begin{tabular}{llcccccc}
\hline Bolts 201-210 & & \multicolumn{8}{c}{ Operational Load (OL) Case } \\
\cline { 2 - 8 } Shear Margin & & $\mathbf{3}$ & $\mathbf{4}$ & $\mathbf{5}$ & $\mathbf{6}$ & $\mathbf{7}$ & $\mathbf{8}$ \\
\hline \multirow{2}{*}{ Baseline Cover } & Worst case Shear Margin & 1.01 & 1.02 & 1.03 & 1.00 & 1.01 & 1.02 \\
\cline { 2 - 8 } & Bolt Number & 210 & 210 & 210 & 210 & 210 & 210 \\
\hline \multirow{2}{*}{ Optimised Cover } & Worst case Shear Margin & 1.00 & 1.02 & 1.03 & 1.00 & 1.00 & 1.02 \\
\cline { 2 - 7 } & Bolt Number & 210 & 210 & 210 & 210 & 210 & 210 \\
\hline
\end{tabular}

The final bolted joint calculation to be carried out was the clamp load margin for both covers under modal forces and the results can be seen in Figures 17 and 18. This is comparing the force as a result of the vibrational acceleration to the available force of the bolt i.e. preload. The figures 16 and 17 show a close trend, highlighting that there is not much change in the forces required from the bolted joint.

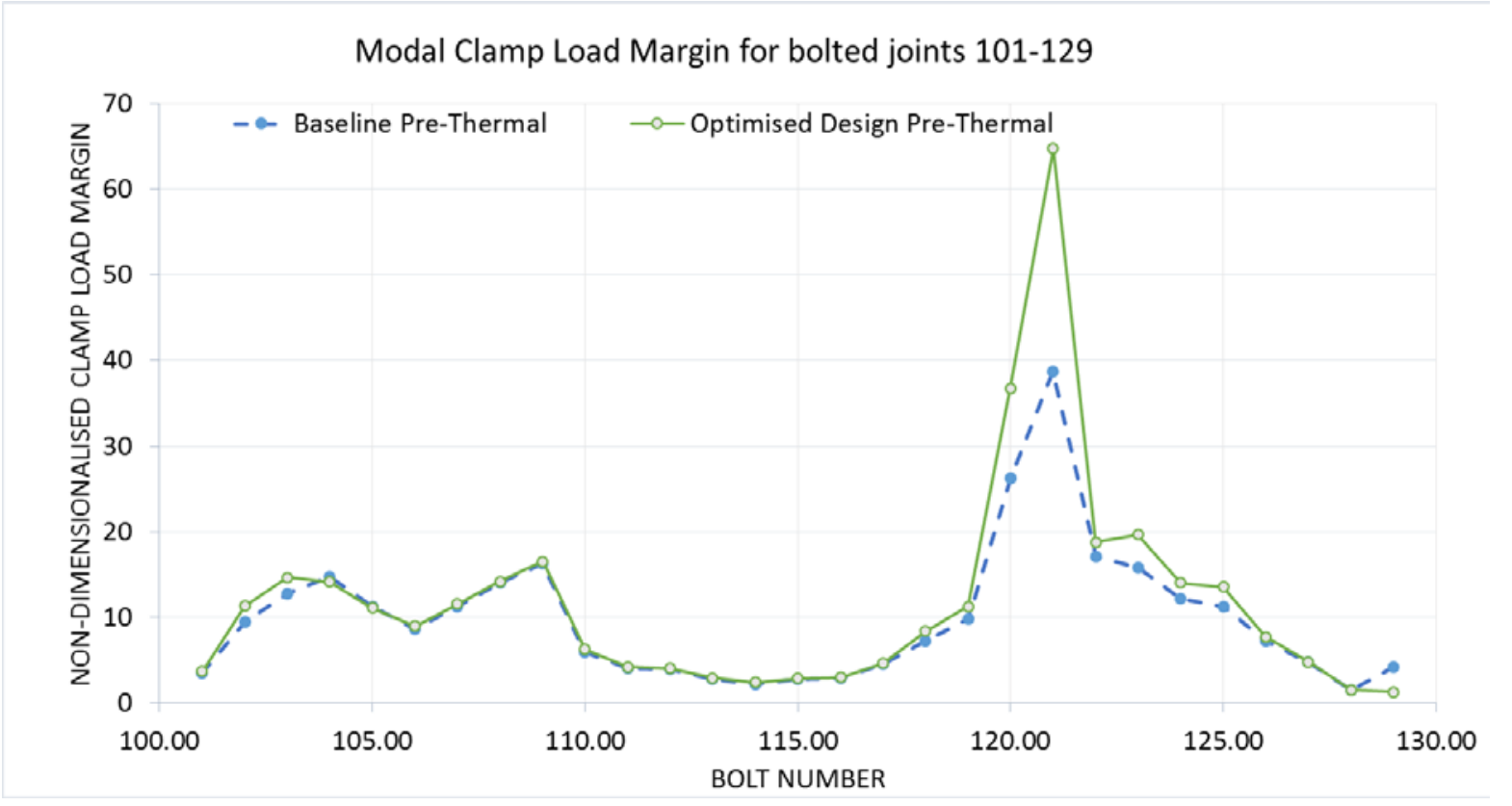

Figure 17: Bolt joint comparison between the baseline cover and optimised cover for clamp load margins of the bolts connecting the aftercooler cover and intake manifold 
Modal Clamp Load Margin for bolted joints 201-210

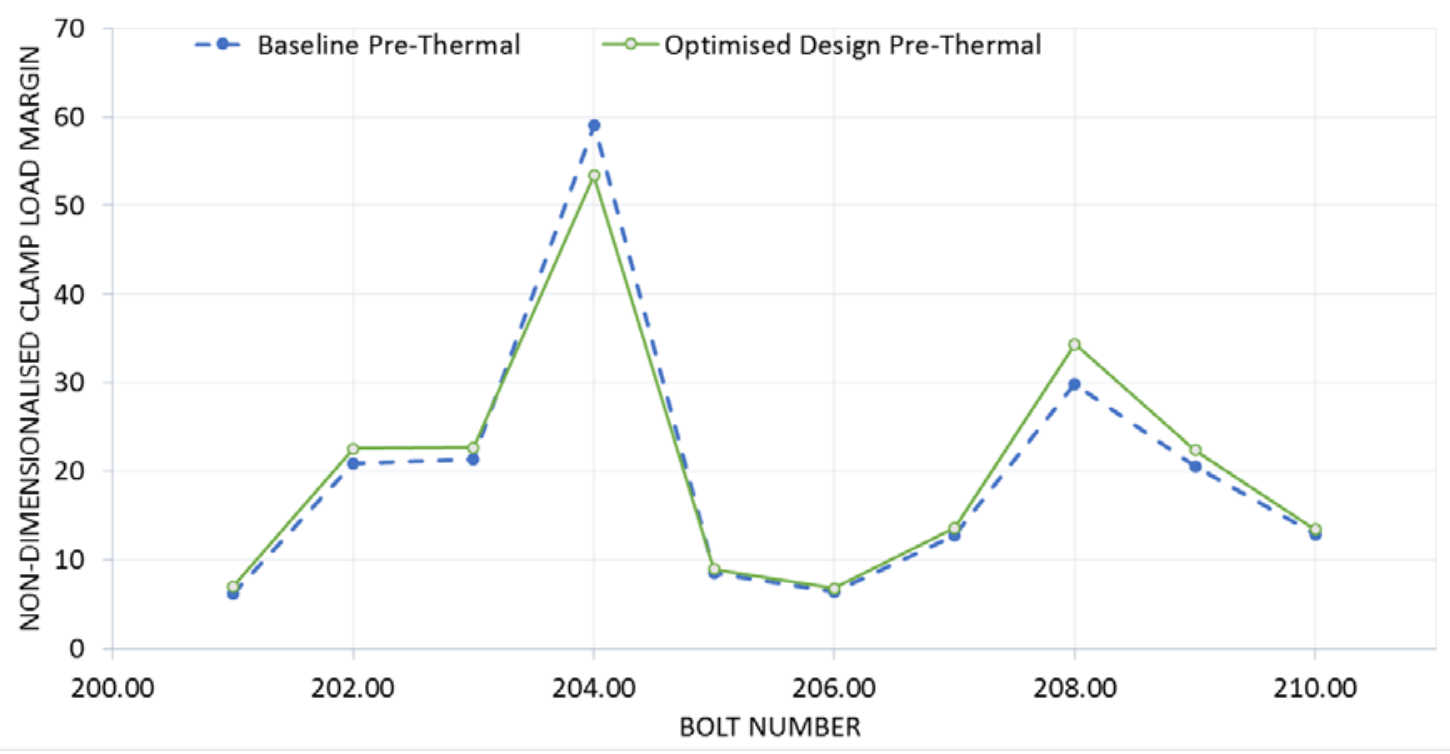

Figure 18: Bolt joint comparison between the baseline cover and optimised cover for clamp load margins of the bolts connecting the aftercooler cover and crossover

\section{Conclusions}

In summary, this method of topology optimisation shows great potential for optimising the aftercooler geometry and structure. This study was limited by constraints as to how much the design could be changed, nevertheless it highlights the real potential that topology optimisation can have, in this particular case even to simply provide direction for design alterations and highlight areas where further material can be removed and make the product more cost effective.

Through this investigation it was observed that there are some key factors that are critical for achieving the optimum solution for the desired problem:

- Remove as much constraint on the topology problem as possible. In this study, not being able to change the internal faces has restricted the full potential of this result.

- Correct material data is essential for carrying out FEA, not just to find the response of the system, but to also evaluate the results.

- It is important to verify the results to ensure they are reliable. 
In this study, topology optimisation has been used to successfully produce an improved design based on the boundary conditions applied to the problem. However, the constraints imposed on the problem, such as keeping the internal faces constant, made it difficult to improve the performance internally as well as externally on the cover. Nonetheless, the optimised aftercooler cover has a reduced weight of $6.5 \%$ and by use of FEA it has been shown that even the worstcase results for the cover are an improvement compared to the current baseline cover. Further work to be carried out includes size optimisation to optimise the dimensions of the design features and material research, giving rise to further weight reductions. Following this, a full costanalysis can be carried out to quantify the cost saving in terms of manufacture, materials, transport, fuel etc.

\section{Acknowledgements}

The authors would like to thank Cummins Inc. for providing the necessary computational tools and representative data throughout.

\section{References}

[1] A. Tiwari, P.N. Hoyos, W. Hutabarat, C. Turner, N. Ince, X.-P. Gan and N. Prajapat, "Survey on the use of computational optimisation in UK engineering companies", CIRP Journal of Manufacturing Science and Technology, pp. 57-68, 2015

[2] M.P. BendsØe and N. Kikuchi, “Generating Optimal Topologies in Structural Design using a Homogenization Method”, Computer Methods in Applied Mechanics and Engineering, pp. 197-224, 1988

[3] S. Johnsen, "Structural Topology Optimization: Basic Theory, Methods and Applications”, Master Thesis, NTNU-Trondheim, Norwegian University of Science and Technology, 2013

[4] C. Mozumder, J.E., Renaud, A. Tovar, “Topometry optimisation for crashworthiness design using hybrid Cellular Automata”, International Journal of Vehicle Design, Vol. 60, No. 12, pp. $100-120$

[5] Board on Energy and Environmental Systems; Division on Engineering and Physical Sciences, Assessment of Technologies for Improving Light Duty Vehicle Fuel Economy, Washington: The National Academies, 2008 
[6] M. Abdi, I. Ashcroft and R. Wildman, "Design optimization for additive manufacture of lightweight automotive components”, 3rd Biennial International Conference on Powertrain Modelling and Control Testing, Mapping and Calibration (PMC2016), Loughborough University, UK, 2016

[7] G. Chiandussi, I. Gaviglio and A. Ibba, “Topology optimisation of an automotive component without final volume constraint specification", Advances in Engineering Software, Vol. 35, No. 10-11, pp. 609-617, 2004

[8] P. Wu, Q. Ma, Y. Luo and C. Tao, “Topology Optimization Design of Automotive Engine Bracket”, Energy and Power Engineering, Vol. 8, pp. 230-235, 2016

[9] M. Shaari, M. Rahman, M. Noor, K. Kadirgama and A. Amirruddin, "Design of Connecting Rod of internal combustion engine: A topology optimization approach”, National Conference in Mechanical Engineering Research and Postgraduate Studies, Pahang, 2010

[10] M. Cavazzuti and L. Splendi, "Structural Optimization of Automotive Chassis: Theory, Set up, Design”, $6^{\text {th }}$ International Conference Problemes Inverses, Controle et Optimisation de Formes (PICOF 2012), Ecole Polytechnique, Palaiseau, France, April $2^{\text {nd }}-4^{\text {th }}, 2012$

[11] M. Cavazzuti, A. Baldini, E. Bertocchi, D. Costi, E. Torricelli and P. Moruzzi, “High performance automotice chassis design: a topology based approach”, Structural and Multidisciplinary Optimization, Vol. 44, No. 1, 2011, pp. 45-56

[12] M.P. Bendsøe and O. Sigmund, “Topology Optimization: Theory, Methods and Applications”, Berlin: Springer-Verlag, 2003

[13] A. Rietz, "Sufficiency of a finite exponent in SIMP (power law) methods", Structural and Multidisciplinary Optimization, Vol. 21, No. 2, pp. 159-163, 2001

[14] O. Sigmund, “A 99 line topology optimization code written in MATLAB,” Structural and Multidisciplinary Optimization, Vol. 21, pp. 120-127, 2001

\section{Abbreviations}

A Assembly

AP Assembly Pressure

CAD Computer Aided Design

CSYS Co-ordinate System

FEA Finite Element Analysis

(c) 2016 Cummins Inc. All Rights Reserved. 
International Journal of Powertrains, 2017 (Accepted Version)

$\begin{array}{ll}\text { FOS } & \text { Factor of Strength } \\ \text { MMA } & \text { Method of Moving Asymptotes } \\ \text { MF } & \text { Mass Fraction } \\ \text { MMI } & \text { Mass Moment of Inertia } \\ \text { OC } & \text { Optimality Method } \\ \text { OL } & \text { Operational Loads } \\ \text { RAMP } & \text { Rational Approximations of Material Properties } \\ \text { RPM } & \text { Rotations per Minute } \\ \text { SIMP } & \text { Solid Isotropic Material with Penalization } \\ \text { SLP } & \text { Sequential Linear Programming } \\ \text { SQP } & \text { Sequential Quadratic Programming } \\ \text { UTS } & \text { Ultimate Tensile Strength }\end{array}$

(c) 2016 Cummins Inc. All Rights Reserved. 